\title{
The Impact of Housing Conditions on the Emotion, Behaviour, and Psychological Wellbeing of Middle-Income Groups
}

\author{
Shadiya Mohamed Baqutayan ${ }^{1}$, Fauziah Raji ${ }^{2} \&$ Aini Suzana Ariffin ${ }^{1}$ \\ ${ }^{1}$ Perdana School of Science, Technology and Innovation Policy, University Technology Malaysia, Malaysia \\ ${ }^{2}$ Faculty of Geoinformation \& Real Estate (FGHT), University Technology Malaysia, Malaysia \\ Correspondence: Shadiya Mohamed Baqutayan, Perdana School of Science, Technology and Innovation Policy, \\ Universiti Teknologi Malaysia, Level 6, Menara Razak, 54100, Jalan Sultan Yahya Petra, Kuala Lumpur, \\ Malaysia. E-mail: shadiya.kl@utm.my
}

Received: April 23, 2015 Accepted: May 12, 2015 Online Published: September 29, 2015

doi:10.5539/jsd.v8n8p262 URL: http://dx.doi.org/10.5539/jsd.v8n8p262

\begin{abstract}
Housing remains a major problem for most, especially for the bottom billions; satisfaction on housing is one of the important indicators that reflect the societal wellbeing. This paper provides a meaning and understanding for the relationship between housing conditions and wellbeing; therefore, it evaluates the impact of housing conditions on the emotion, behaviour and psychological wellbeing of middle-income group in Malaysia. In fact, the housing conditions in this research include home size, housing features, as well as safety and security. Respondents of 390 were randomly selected from those middle-income houses in Kuala Lumpur and Johor Bahru (Skudai). The accumulated data were then analysed and descriptive statistics were used to interpret and evaluate the impact of housing condition on wellbeing. The finding showed small but significant positive relationship between housing conditions and psychological wellbeing. However, housing conditions is the contributing factors, which negatively affect the behaviour and attitude of middle-income group children. Overall, this research supports the critical link between good housing condition that is decent, safe, secure, and affordable and positive health outcome.
\end{abstract}

Keywords: housing condition, housing and wellbeing, emotion, behaviour and psychology of housing

\section{Introduction}

The Malaysian housing policy has developed since its independence from the British in 1957; this policy has pledged to improve housing quality and affordability for all citizens (Salfarina, Nor Malina, \& Azrina, 2011). Despite the ambitious nature of this commitment, public policy have paid little attention on the impact of housing condition on dweller's lives and psychological wellbeing.

Issues of housing and wellbeing have become increasingly important in developed countries, and the home environment is of tremendous significance to human beings. The relationship between housing conditions and health has been of policy interest since 1842 when Chadwick noted the low life expectancy of cellar dwellers. The 1998 Acheson Report identified housing and environment as an importance area for reducing health inequalities; concerns repeated a decade later by Marmot in 2010 (Barnes et al, 2013).

It is indeed a tough task to define the relationship between housing conditions and wellbeing developing countries. Although, it has been proven that good housing condition is a key element for ensuring a healthy society (Howard, 2002); whereas the poor housing condition can have an adverse effect on the family's psychological wellbeing (Minton \& Jones, 2005). Essentially, it is important in this paper to explain the relationship between housing and wellbeing; the aim is to describe the impact of housing conditions on the behaviour, emotions, and psychological wellbeing of middle-income groups in Malaysia. Based on the subjective matter of this research, qualitative approach was used to facilitate the collecting data.

\subsection{The Concept of Housing and Housing Conditions}

Housing was defined as a place of attachment (Eshelman, Evans \& Kantrowitz, 2002), intentions to relocate (Earhart \& Weber, 1996), and residential satisfaction (Christensen, Carp, Cranz, \& Wiley, 1992). Knowing that absent of the house is assessments of mental health. Housing is a basic human need that Maslow explained in the hierarchy of needs; and it is the first level of need similar to food and drink (Manitoba, 2012). Housing is not just 
a physical shelter of four walls and a roof; it is about the quality and condition that was expanded in the second level of Maslow hierarchy of need. At this level, Maslow's theory demonstrates on how important adequate housing is for the security and positive development (Martin \& Joomis, 2007). Housing usually has a significant impact on dweller's safety and wellbeing. An unsafe environment, for instance, increases the likelihood of harm and injury, which could have implications for the whole family's wellbeing. Housing in poor condition is more likely to contain hazards that could create an unsafe environment for the whole family (Ford, et al, 2004).

The provision of adequate, good quality housing for the population has always been a major challenge and task for most nations in the world particularly the developing countries. As such various measures have been undertaken towards this end. However, the major constraint in this respect has always been in defining the criteria for good housing and the impact of poor housing conditions on the psychological wellbeing. This paper is aiming to discuss in detail the concept of housing and housing conditions. In fact, any definition of housing condition needs to encompass on a range of factors that determine the house to be good/bad (Barnes et al, 2013). The obvious one is the physical condition; housing may be deemed to be bad if it is damp, infested, cold, or in a bad state of repair. Housing may also be considered to bad if it is unable to accommodate the number of people inhabiting it. The environment in which the housing is located is also important. Relevant neighbourhood factors include access to amenities, and environmental pollution is also essential. Security of tenure, the status people attach to housing and the levels of community safety and cohesion in an area are all important features.

Housing size, quality, neighbourhood, location and household composition in any analysis of housing seems to be very important measure (Rowley \& Ong, 2012). According to Stone (2006) "Housing quality can not be ignored". The wider concept of "housing" need encompasses many of subjects like housing size, quality, neighbourhood, location, and household composition (Stone, 2006). In deed, many more can be said on housing condition, but the important argument is on the relationship between housing conditions and wellbeing.

\subsection{The Impact of Housing Conditions on Wellbeing of Middle-income Groups}

Mainly, it is difficult to determine the relationship between housing and health because of many variables that are associated with a person's wellbeing. The strength and direction of this relationship, however, remains somewhat contested. A review of academic literature has drawn together strong evidence of the direct impact of bad housing, poor housing conditions, homelessness, and overcrowding on dwellers' life chances. However, given the clear link, the volume of high quality research in this area is surprisingly limited and there is an urgent need for more comprehensive research in this area. Furthermore, areas where the need for further research is particularly pressing are the psychological, social or behavioural effects of poor physical environments; the impact of poor housing on particularly vulnerable groups; and the impact of interventions set up to address housing problems (Breysse, et al., 2004). Hence, this research concern about how housing conditions can affect the behavior, emotion and psychological wellbeing of middle-income groups.

It is great to mention that a safety shelter is the second level of need that contributes to the physical, psychological and emotional wellbeing of the person. There is a strong and well-documented relationship between housing quality and physical and mental health problems (Payne, 2006). Quality of housing at this point may refer to lack of safety, dirty conditions, and sharing of rooms or amenities. Apart from quality of housing, the size of accommodation relative to the number of inhabitants is a key indicator (Atkinson, Cantillon, Marlier, \& Nolan, 2002).

Studies have found that poor quality housing can cause psychological stress (Kearns \& Smith 1993; Dunn 2002) and can negatively impact self-esteem and family self-sufficiency (Evans et al. 2000; Bratt 2002). Some of the factors contributing to these mental issues include "anxiety about structural hazards, worry and lack of control over maintenance and management practices, and fear of crime" (Evans et al. 2000).

Grayling, et al., (2002) indicated that the dwellers living in deprived areas, where the incidence of poor housing is often highest, are three more times likely to be in dangers. Furthermore, Fujiwara (2013) find that those living in a household with pollution, grime or other objective environmental problems with their housing have reduced life satisfaction. Whereas, a dweller's perceived level of safety in their home or local community may also have an impact on their emotional wellbeing (Blackman, et al., 2001). Poor quality housing negatively also influences a child's behaviour and ability to focus at school, increasing stress and causing poor health or attendance that leads to poor academic performance (Braconi 2001).

\subsection{The Objective}

The main objective of this paper is to measure the impact of housing conditions on the attitude, behaviour, emotions, feelings and psychological wellbeing of middle-income groups. 


\section{Method}

The study is purely based on a quantitative method. 400 residents from middle-income groups were requested to answer the questionnaire that measures "housing conditions and wellbeing". Participants were from two urban states in Malaysia; Kuala Lumpur and Johor Bahru (Skudai). The sampling method was based on purposive sampling, focusing on middle-income housing areas. The targeted number of sampling was 200 respondents from each state, and the number of answered script received were 390 from both stats.

\section{Results}

The scale used on this study focuses on housing quality and its impact on wellbeing. Frequency was used to calculate the number and percentage of respondents' answer to all questions. The results were highlighted as followed:

\subsection{Demographic Variable}

The majority of respondents were Malays $75.13 \%$ whose age group was below 40 -years old $(66.66 \%)$, earn between RM1001-RM3000 monthly, and not afford to buy a house $(90.51 \%)$ because the price is too high $(81.03 \%)$. This signified that the salary average in Malaysia is very low; add into the fact that the big danger is the massive increase of housing price in Malaysia. According to Yin Shao Loong (2014), in 2013, the median salary for Malaysians was RM1700 per month. For non-Malaysians it was RM980. In 2013, 50\% of Malaysians earned RM1700 and below per month. The largest share of household expenditure was spent on housing, water, electricity, gas and other fuels, followed by food and non-food beverages, transport, and restaurants. This outcome is very serious; when housing costs make up a large share of the household budget, and low/middle-income population is often constrained by the level of resources left for other necessary expenditures, such as food, healthcare and education. High housing costs can thus threaten wellbeing and economic security of the whole family. They may also generate forms of housing stress that may seriously hamper relations between all members of the house.

\subsection{The Impact of Housing Conditions on the Emotional Wellbeing}

The scale used in this study focused on the impact of housing condition on the emotion of Middle-income group. Frequency was conducted to calculate the number and percentage of respondents' answer to "Yes" or "No" questions. The results are highlighted as followed:

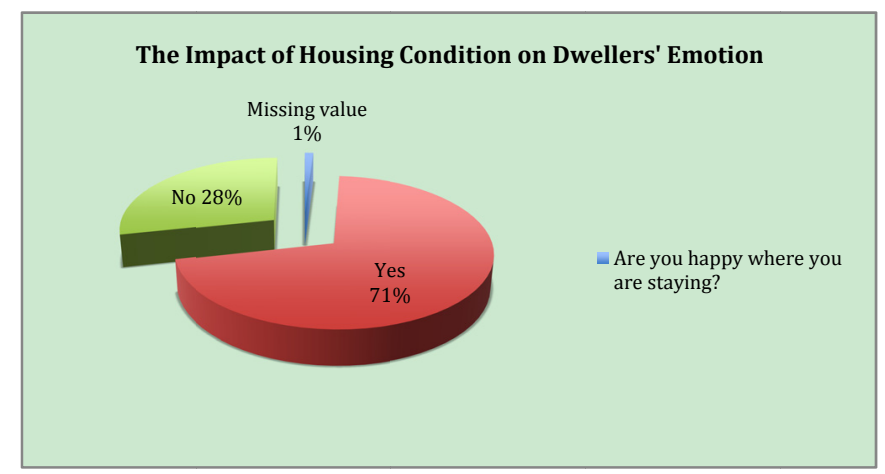

Figure 1. Impact of housing condition on the emotion of middle-income group

The above figure (1) identifies the emotion and feeling of participants toward the place they are livening. The outcome is very obvious; most of the respondents (71\%) are happy and satisfied with the place where they stay, and only $(21 \%)$ are not. The happiness in this context is not associated with the housing conditions; there must be other reasons make them happy to stay in the place they are living. Because respondents overall complain about housing conditions (will be highlighted later). According Ratcliffe (2010), happiness associated with housing price; happier people are those live in areas with systematically lower house prices, rising house prices could have a direct effect on people's happiness. This means that the effect of house prices on happiness is identified by changes over time. And our respondents are happy because of the housing price that suite their income and not because of the housing conditions and quality. 


\subsection{The Impact of Housing Conditions on Psychological Wellbeing}

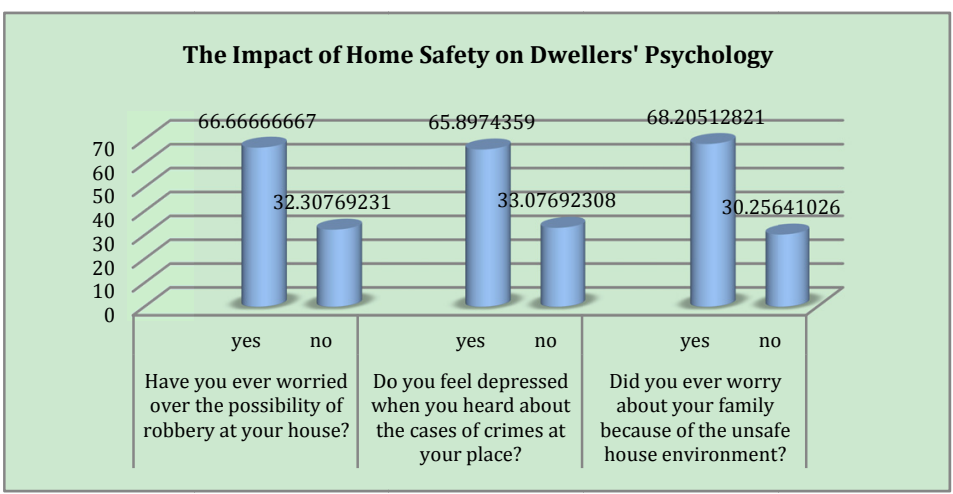

Figure 2. Impact of housing safety on the psychological wellbeing of middle-income group

The above figure (2) showed that the majority worries about safety and the security of their living environment. They worried over the possibility of robbery at their house, they also depressed when they heard about the cases of crimes at their place, and they always worry about their family's safety because of the unsafe house environment. This outcome signified that home safety and security are very important elements that contribute to the wellbeing of any individual; unsafe conditions can threaten the entire residents' wellbeing. Similarly indicated by Center (2011) that the link between safe and adequate housing and wellbeing is very strong; safety home plays an important role in influencing the lives and life of the entire families, and living in a distressed area irritates wellbeing.

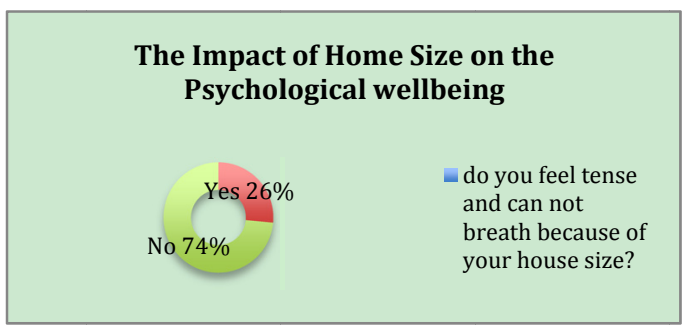

Figure 3. Impact of housing size on psychological wellbeing

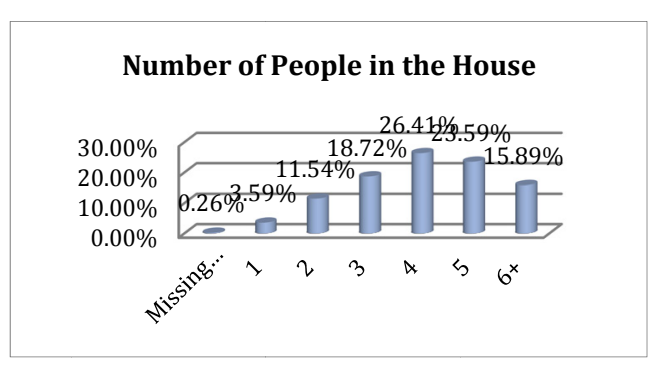

Figure 4. Number of people in the house
Table 1. Cross tabulation between home Size and number of people

\begin{tabular}{|c|c|c|c|c|}
\hline \multicolumn{5}{|c|}{$\begin{array}{l}\text { Do you feel tense and can not breath because of } \\
\text { your house size? }\end{array}$} \\
\hline \multirow{8}{*}{ 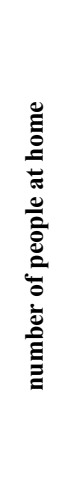 } & & $\begin{array}{c}\text { missing } \\
\text { value }\end{array}$ & yes & no \\
\hline & missing value & 0 & 1 & 0 \\
\hline & 1 & 0 & 4 & 10 \\
\hline & 2 & 0 & 14 & 31 \\
\hline & 3 & 0 & 13 & 60 \\
\hline & 4 & 2 & 29 & 72 \\
\hline & 5 & 0 & 25 & 67 \\
\hline & $6+$ & 3 & 16 & 43 \\
\hline Total & & 5 & 102 & 283 \\
\hline
\end{tabular}

The above figure (3) indicated that "home size" is not really stressing the respondents of this study; the majority $72.50 \%$ are not tense because of home size. The reason could be because the number of people living in the home is not too big. It is indicated in figure (4) that the majority of our respondents were small family; they were between 3-5 people in one house. To be more accurate "cross tabulation" was done between home size and number of people at home as shown in table (1). The result indicated that majority who answered "no" to whether they are tense because of home size were those 3-5 people in one home. This signifies that the middle-income home size in Malaysia suites the numbers of people living on it, therefore, majority was not complaining about home size. But this outcome does not mean at all that family in an overcrowding home are not tense and the home size does not influence their wellbeing. Because researchers indicated that crowding house has detrimental effects on both mental and physical health (Evans, 2001). 
To be more detail the other features of home were measured in relation to wellbeing as followed:

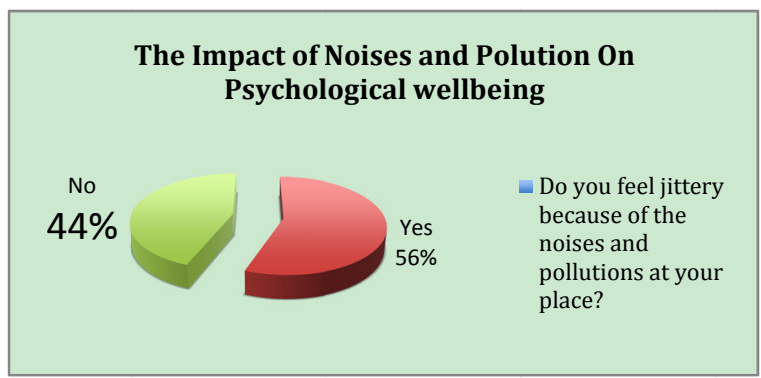

Figure 5. Impact of noises and pollution on the psychological wellbeing of middle-income group

The above figure (5) indicated that the majority complains about the noises and pollution; $56 \%$ of the respondents feel jittery because of the noises and pollutions at their place. This is signified that noses and pollution has an impact on the psychological wellbeing. According to Evans (2002), housing type and quality, neighbourhood quality, noise, crowding, indoor air quality, and light have all been linked to personal mental health. Loud exterior noise sources elevate psychological distress; Guite et al. (2006) confirmed an association between the physical environment and mental wellbeing across a range of domains. The most important factors that operated independently were neighbour noise, sense of over-crowding in the home and fear of crime. This study highlighted the need to intervene noise and pollution to promote mental wellbeing.

Finally, housing condition and psychological wellbeing was analysed as followed:

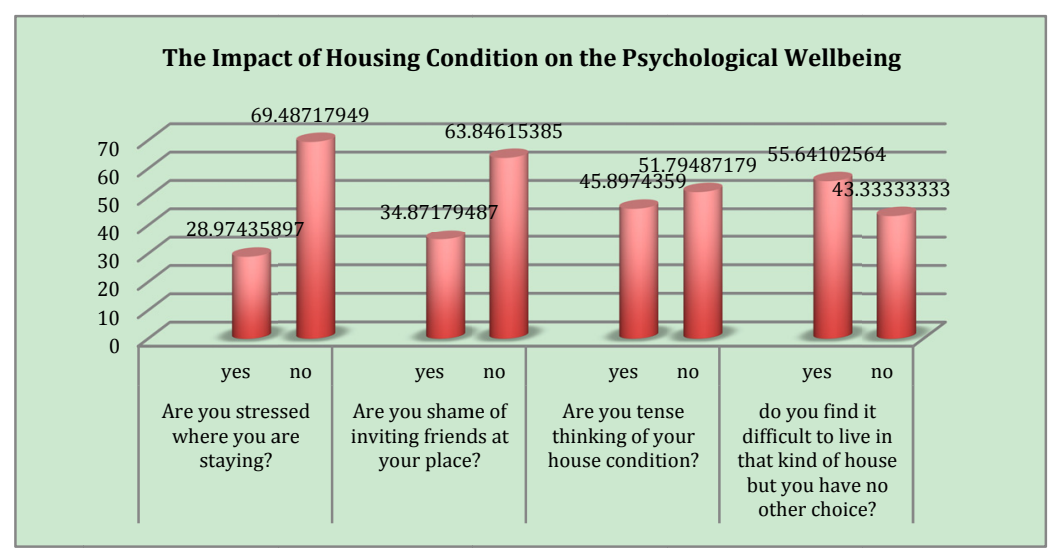

Figure 5. Impact of housing conditions on the psychological wellbeing of middle-income group

The above figure (5) indicated that housing condition has a great impact on the psychological wellbeing of participants. As shown, the majority complains about their housing conditions. They were stressed of the place where they are living, shame of inviting friends at their place, tense thinking of their house condition, and they find it difficult to live in this kind of house but they have no other choice. This out come from the psychological point of view is expected, because stressful and poor living conditions can cause continuing feelings of shame, insecurity and worthlessness. Therefore government need to look into this issue and help the middle-income groups improve their home conditions. 


\subsection{The Impact of Housing Conditions on Behavioral Wellbeing}

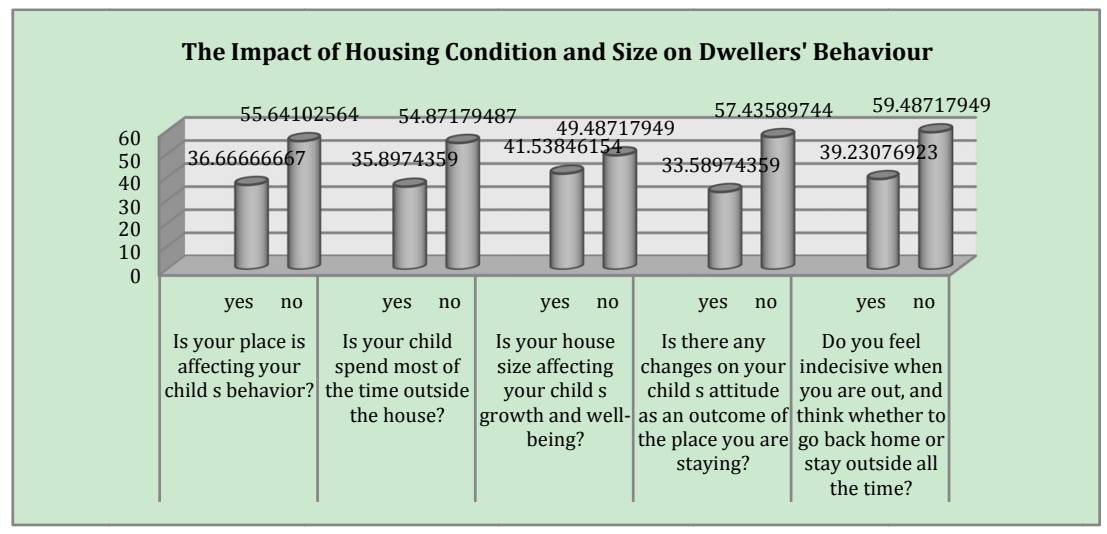

Figure 6. Impact of housing conditions and size on the behavioural wellbeing of participants

Almost half of the participants described their housing conditions as a contributing factor, which negatively affect their children's behaviour and attitude. To be more specific, $(36.60 \%)$ of the respondents complained about the place they are living; according to them the changes on their child's behaviour and attitude is a result of the place and environment they are living. Additionally, (35.89\%) of them evaluated their children loafing behaviour and spending most of their time out is because of home conditions and size. Furthermore $(41.53 \%)$ of the respondents indicated that home size is a contributing factor to child's growth and wellbeing. Finally, (39.23\%) of them indicated that they feel indecisive when you are out, and think many times whether to go back home or stay outside all the time. This issue is vey serious, people need vital solution to their problems. Government need to help and support those families whose children emotion, attitude and behaviours are affected because of home conditions. Managing the children behaviour is very important; therefore, support may also be needed from school, family, neighbours, or psychologists.

\section{Discussion}

Housing circumstances often have a direct impact on family's health, which in turn significantly affects their emotion, behaviour and psychological wellbeing. In the past, housing was not big issue as the populations were less and the houses were more, cheap, big and safe. But now the issue is just the opposite, the populations are getting bigger and the houses are becoming more expensive, small in size and not safe at all. In fact, this issue will become ever more critical and complicated in the future. Therefore, the need for housing should be included in the country vision and mission, if not, the key needs for the low and middle-income populations may be missed.

The current research offers strong support for the views that if housing quality were decreased the households wellbeing would also decline. In this research, the main factors contributed to the wellbeing of middle-income groups are: home size, safety and security, housing feature and conditions, as well as noises and pollution. The objective of this study was to analyse the impact of housing condition on the wellbeing of middle-income groups. The findings clearly indicated the followings: (a) majority of the respondents were middle and low-household income groups, they monthly earn between RM1001-3000; (b) inconsistency between housing prices and income level of the participants; (c) the majority were complaining about housing price, features, size, safety, and pollution; (d) noises and pollution stresses majority of respondents; (e) housing condition has a great impact on the psychological wellbeing of middle-income groups; (e) majority of the respondents complain more about housing conditions as a contributing factors, which negatively affect their children's behaviour and attitude.

Several conclusions can be drawn from this discussions and outcomes. First, housing condition is a difficult concept to define, because it involves individual judgments and different evaluations, in this research, for instance, people complain about housing condition, yet they are happy and satisfied with the place where they stay. Second, evaluations on the impact of housing conditions will likely continue to vary because it is unlikely that all researchers will agree upon the same set of assumptions and measures to use when quantifying housing quality, housing size and housing features. Third, there are many more factors contributing to wellbeing of middle-income groups that need to be considered in future research. Fourth, Government must work hard to improve the housing conditions for all citizens without too much of burden to those in the low and middle-income groups. 
From an implementation point of view, the present research findings can be used to tackle the impact of housing conditions on the behaviour and psychological wellbeing of middle-income groups, and emphasizes on the need for more safety and good condition houses. In conclusion, a review of academic literature has drawn together strong evidence of the direct impact of housing on wellbeing. However, given the clear link, the volume of high quality research on this area is surprisingly limited and there is an urgent need for more comprehensive research.

\section{Acknowledgments}

I would like to express my special thanks of gratitude to The Ministry of Education as well as Universiti Teknologi Malaysia (UTM) who gave me the golden opportunity to do this wonderful project, which also helped me in doing a lot of publications and I came to know about so many new things I am really thankful to them. My sincere thank also to all my colleagues who kindly provided valuable and helpful comments of this paper.

\section{References}

Atkinson, A. B., Cantillon, B., Marlier, E., \& Nolan, B. (2002). Social indicators: the EU and social inclusion. Oxford: Oxford University Press. http://dx.doi.org/10.1093/0199253498.001.0001

Barnes, M. et al. (2013). People living in bad housing - numbers and health impacts. NatCen Social Research. Retrieved April 2, 2015, from http://england.shelter.org.uk/_data/assets/pdf_file/0010/726166/People_living_in_bad_housing.pdf

Blackman, T., Harvey, J., Lawrence, M., \& Simon, A. (2001). Neighbourhood renewal and health: evidence from a local case study. Health \& Place, 7, 93e103. http://dx.doi.org/10.1016/S1353-8292(01)00003-X

Braconi, F. (2001). Housing and schooling. The Urban Prospect, 7, 1-4.

Bratt, R. (2002). Housing and family well-being. Housing Studies, 17(1), 13-26. http://dx.doi.org/10.1080/02673030120105857

Breysse, P. et al. (2004). The Relationship between Housing and Health: Children at Risk. Environmental Health Perspectives, 112(15), 1583-1588. http://dx.doi.org/10.1289/ehp.7157

Center for the Study of Social Policy. (2011). Affordable Housing as a Platform for Improving Family Well-Being: Federal Funding and Policy Opportunities. Financing Community Change Brief June 2011. $\begin{array}{llll}\text { Retrieved } \quad \text { April } & \text { 2015, from }\end{array}$ http://www.cssp.org/publications/neighborhood-investment/financing-community-change/Affordable-Housi ng-as-a-Platform-for-Improving-Family-Well-Being-June-2011.docx.pdf

Christensen, D., Carp, F., Cranz, G., \& Wiley, J. (1992). Objective housing indicators as predictors of the subjective evaluation of elderly residents. Journal of Environmental Psychology, 12, 225-236. http://dx.doi.org/10.1016/S0272-4944(05)80137-9

Dunn, J. R. (2002). Housing and inequalities in health: A study of socioeconomic dimensions of housing and self-reported health from a survey of Vancouver residents. Journal of Epidemiology and Community Health, 56, 671-681. http://dx.doi.org/10.1136/jech.56.9.671

Earhart, C., \& Weber, M. (1996). Attachment to home: A contributing factor to models of residential mobility intention. Family and Consumer Science Research Journal, 24, 422-437. http://dx.doi.org/10.1177/1077727X960244007

Eshelman, P., Evans, G. W., \& Kantrowitz, E., (2002). Housing quality and psychological well-being among the elderly population. Journals of Gerontology, Series B: Psychological Sciences and Social Sciences, 57, 381-383. http://dx.doi.org/10.1093/geronb/57.4.P381

Evans, G. et al. (2000). Housing quality and mental health. Journal of Consulting and Clinical Psychology, 68(3), 526-530. http://dx.doi.org/10.1037/0022-006X.68.3.526

Evans, G. W. (2001). Environmental stress and health. In A. Baum, T. Revenson, \& J. E. Singer (Eds.), Handbook of Health Psychology (pp. 365-385). Mahwah, NJ: Erlbaum.

Evans, G. W. (2002). Child Development and the Physical Environment. Annual Review of Psychology, 57(1), 423-451. http://dx.doi.org/10.1146/annurev.psych.57.102904.190057

Ford, J., Quilgars, D., Burrows, R., \& Rhodes, D. (2004). Home-owners Risk and Safety-Nets: Mortgage Payment Protection Insurance (MPPI) and beyond. London: Office of the Deputy Prime Minister

Fujiwara, D. (2013). The social impact of housing providers. Housing, people and communities (HACT). Retrieved 
http://www.hact.org.uk/sites/default/files/uploads/Archives/2013/02/The\%20Social\%20Impact\%20of\%20H ousing\%20FINALpdf.pdf

Grayling, T., Hallam, K., Graham, D., Anderson, R., \& Glaister, S. (2002). Streets Ahead; Safe and Liveable Streets for Children. Institute for Public Policy Research.

Guite, H. F., Clark, C., \& Ackrill, G. (2006). The impact of the physical and urban environment on mental well-being. Public Health, 120, 1117-1126. http://dx.doi.org/10.1016/j.puhe.2006.10.005

Howard, G. et al. (2002). Healthy Villages: A guide for communities and community health workers. World Health Organization Geneva. Retrieved April 13, 2015, from http://whqlibdoc.who.int/publications/2002/9241545534.pdf

Kearns, R. A., \& Smith, C. J. (1993). Housing stressors and mental health among marginalized urban populations. In 2000 Housing and health inequalities: Review and prospects for research, ed. J. Dunn. Housing Studies 200015 (3): 341-366.

Manitoba. (2012). All aboard: Manitoba's poverty reduction \& social inclusion strategy. Retrieved August 4, 2014, from http://www.gov.mb.ca/fs/allaboard/pubs/strategy_paper.pdf

Marmot review. (2010). Fair Society, Healthy Lives, Strategic Review of Health Inequalities in England post 2010.

Martin, D., \& Joomis, K. (2007). Building Teachers: A Constructivist Approach to Introducing Education, (Belmont, CA: Wadsworth, 2007), pp. 72-75.

Minton, A., \& Jones, S. (2005). Generation Squalor. Shelter's National Investigation into the Housing Crisis. Shelter. Retrieved December 22, 2005, from http://england.shelter.org.uk/policy/policy-825.cfm/plitem/169

Payne, S. (2006). Mental health, poverty and social exclusion. In C. Pantazis, D. Gordon, \& R. Levitas (Eds.), Poverty and social exclusion in Britain (pp. 285-311). Bristol: University of Bristol.

Ratcliffe, A. (2010). Houses and happiness. Research in Public Policy Winter 2010. Retrieved April 17, 2015, from http://www.bristol.ac.uk/media-library/sites/cmpo/migrated/documents/ratcliffe.pdf

Rowley, S., \& Ong, R. (2012). Housing affordability, housing stress and household wellbeing in Australia. Retrieved May 27, 2014, from http://www.ahuri.edu.au/downloads/publications/EvRevReports/AHURI_Final_Report_No192_Housing_af fordability_housing_stress_and_household_wellbeing_in_Australia.pdf

Salfarina, A. G., Nor Malina, M., \& Azrina, H. (2011). Trends, Problems and Needs of Urban Housing in Malaysia. International Journal of Social, Education, Economics and Management Engineering, 5(2).

Stone, M. E. (2006). What is Housing Affordability? The Case for the Residual Income Approach. Housing Policy Debate, 17(1), 151-184. http://dx.doi.org/10.1080/10511482.2006.9521564

Yin Shao Loong. (2014). Key Statistics. InstitutRakyat, 1(1), 1-3.

\section{Copyrights}

Copyright for this article is retained by the author(s), with first publication rights granted to the journal.

This is an open-access article distributed under the terms and conditions of the Creative Commons Attribution license (http://creativecommons.org/licenses/by/3.0/). 